\title{
LEITURA LITERÁRIA NA EJA: QUESTIONANDO A IDENTIDADE SEXUAL
}

\author{
Fábio Silva Santos ${ }^{1}$ \\ Carlos Magno Gomes ${ }^{2}$
}

\begin{abstract}
Resumo. Este artigo apresenta uma proposta de letramento literário para turmas da Educação de Jovens e Adultos (EJA) do Ensino Fundamental a partir do debate em torno das identidades sexuais e da ambiguidade com a qual esse tema é abordado por Clarice Lispector no conto $O$ corpo, da coletânea $A$ via crucis do corpo (1974). Metodologicamente, aplicamos os conceitos teóricos ligados à formação do leitor: identidade literária, proposto por A. Rouxel; Prática cultural de leitura, articulado por C. Gomes; e leitura literária na EJA, defendido por M. Cruz. Como resultado desta pesquisa, apresentamos o relato de uma experiência de leitura que teve o objetivo de ampliar o horizonte de expectativa do leitor no que se refere à flexibilidade das identidades sexuais.
\end{abstract}

Palavras-chave. EJA. Letramento literário. Identidades sexuais.

\section{LITERARY READING IN EJA: QUESTIONING THE SEXUAL IDENTITY}

\begin{abstract}
This article presents a proposal of literary literacy for classes of Youth and Adult Education (EJA, in Portuguese) of Elementary School from the debate about sexual identities and the ambiguity as this theme is approached by Clarice Lispector in the short-story "O corpo" of the book $A$ via crucis do corpo (1974). Methodologically, we applied the theoretical concepts related to the formation of the reader: "literary identity", proposed by A. Rouxel; "literary literacy", articulated by C. Gomes; and "literary reading" in EJA, defended by M. Cruz. As a result of this research, we present the report of a reading experience that aimed to broaden the reader's expectation horizon regarding the flexibility of sexual identities.
\end{abstract}

Keywords. EJA; Literary literacy; sexual identities.

\footnotetext{
${ }^{1}$ Mestre em Letras pelo PROFLETRAS/UFS (2016). Bolsista CAPES. Professor da SEED-SE.

2 Doutor em Literatura. Professor da UFS/CNPq. Pesquisador em estágio de pós-doutorado em Antropologia Social pela UnB. Endereço eletrônico: calmag@bol.com.br.
} 


\section{Introdução}

Apresenta-se neste artigo uma experiência de leitura literária realizada numa turma da EJAEF II de uma escola pública do estado de Sergipe. Essa proposta de trabalho promove a discussão sobre as identidades sexuais contemporâneas a partir de uma abordagem cultural segundo a qual o texto literário traz discussões relacionadas às diversas identidades que circulam socialmente. Para isso, propomos oficinas de leitura do texto literário com o objetivo de promover a ampliação do horizonte de expectativa do leitor. Como corpus literário, selecionamos a representação das identidades sexuais da obra $A$ via crucis do corpo (1974), de Clarice Lispector. Para este artigo, vamos apresentar os resultados das oficinas de leitura do conto $O$ corpo, ressaltando que os contos Ele me bebeu e $A$ via crucis do corpo também foram explorados durante nossas oficinas de vivência literária.

Metodologicamente, partimos das considerações de Maria de Fátima Berenice da Cruz, que ressalta a apropriação do texto literário como uma experiência de leitura de enriquecimento de nossas aulas da EJA, visto que os jovens e adultos trazem vivências sociais que ampliam o processo de interpretação. Com essa particularidade, esses sujeitos devem ser considerados "como parte integrante do ato da leitura" (CRUZ, 2012, p. 190). $\mathrm{Na}$ realização deste trabalho, as ações promovidas estavam centradas na reação desse sujeito diante da experiência estética e cultural da leitura do texto literário.

Nesse processo, espera-se que o leitor explore seu conhecimento de vida como um dos recursos para a interpretação dos sentidos do texto literário. Conforme Umberto Eco, cabe ao leitor o trabalho de preencher os espaços em branco a partir de dois motivos básicos: primeiro porque o texto é um mecanismo econômico, ou seja, precisa da ação do destinatário para gerar seu sentido; segundo porque, considerando sua função estética, o texto quer que o leitor tenha uma atitude interpretativa, ainda que costumeiramente essa interpretação ocorra dentro de determinados limites (ECO, 2004, p. 37).

Nessa perspectiva, o leitor é convidado a assumir a condição de coautor da obra, isso porque "todo texto quer que alguém o ajude a funcionar" (ECO, 2004, p. 37). Desse modo, qualquer sujeito real que se dedique a realizar 
a leitura de uma obra, embora não seja aquele leitor idealizado pela estrutura do texto - porque ninguém pode ser - assume a função de cooperar com o processo de atualização dos significados do texto. Assim considerando, chegase ao reconhecimento de que não se pode dar menos crédito à interpretação do leitor das turmas de EJA sob o pretexto de que suas análises não fazem sentido ou são insuficientes.

Esta experiência tem a peculiaridade de explorar a perspectiva cultural de apropriação da obra literária. Nesse modelo de leitura, o aluno precisa ser incentivado a aplicar questões culturais presentes no texto para, a partir daí, lançar-se na tarefa de atualizar os significados da obra literária. Nessa direção, a prática cultural de leitura reforça a ampliação do horizonte de expectativa do leitor, que passa pelo processo de identificação do seu "pertencimento identitário" e de "sua capacidade de aceitação e reconhecimento das diferenças que perpassam o pertencimento do outro" (GOMES, 2014, p. 29). Para nossas oficinas, enfatizamos as questões sobre a identidade sexual e as ambiguidades do texto literário de Clarice Lispector.

Para o estudo dos dados sobre a recepção dos textos literários, optou-se pela realização de uma atividade de produção de textos através da qual os alunos puderam expressar sua compreensão sobre os contos lidos. Tal procedimento foi adotado a partir da valorização da leitura do texto literário e da produção de um texto com os resultados dessa interpretação (XAVIER, 2014, p. 11). Os textos produzidos pelos alunos nessas atividades constituíram um importante registro do nível de apreensão da leitura e sua análise revelou os caminhos por eles seguidos para atuarem sobre o texto literário, levando para a obra suas experiências de vida e dela extraindo também uma nova compreensão sobre as diferentes identidades sexuais, que fazem parte da contemporaneidade.

Na realização deste trabalho, portanto, foram considerados quatro elementos fundamentais: 1- as características dos alunos da EJA; 2- os aspectos estéticos e socioculturais representados na obra literária; 3- a prática docente aplicada ao trabalho de leitura; e, 4- as contribuições que os estudos teóricos oferecem hoje à prática da leitura literária. A partir desses elementos, foram organizadas as oficinas de leitura nas quais o leitor foi convidado a atuar de 
forma crítica e criativa para poder colaborar de fato com a produção de significados para os textos lidos. Na sequência, apresentamos algumas reflexões teóricas sobre a leitura literária e as etapas das oficinas com os resultados alcançados.

\section{Experiências e vivências culturais}

Para obter informações sobre as concepções de leitura dos alunos da EJA, foi explorado o espaço de convivência da leitura. Nessa ocasião, foram propostas para o grupo, de forma gradativa, diversas questões sobre seus hábitos de leitura, tipos de leitura que preferem realizar, interesse por histórias de ficção e relações que eles percebem entre as histórias que eles leem e a realidade na qual eles vivem. A partir dessa conversa, pôde-se constatar que, para esses alunos, o ato de ler obras literárias limita-se às poucas atividades realizadas pela escola.

Essa leitura ocorre, quase que exclusivamente, através do livro didático disponibilizado pelo Programa Nacional do Livro Didático. Além disso, evidenciou-se que esses alunos não fazem distinções claras sobre o tipo de leitura que gostam de realizar - foram citados por eles, além do livro didático, textos bíblicos, panfletos, revistas em quadrinhos e piadas postadas em aplicativos de comunicação instantânea. Com relação à leitura de textos de ficção, os participantes das nossas oficinas demonstraram já ter consciência de que os fatos apresentados na obra literária não correspondem fielmente aos fatos da realidade. Eles reconhecem que, por meio da leitura, podem exercitar a capacidade de se colocarem no lugar de outros sujeitos - as personagens - para experimentar outras formas de viver, sem, contudo, deixarem de ser eles mesmos.

Nesta experiência de vivência da leitura, pôde-se perceber que, inicialmente, a leitura literária era vista por eles como uma atividade irrelevante, marcada por um certo distanciamento. Todavia, com a execução das oficinas, pudemos perceber que alguns alunos passaram a explorar de forma significativa os aspectos estéticos e ambíguos do texto literário. 
Esse distanciamento é resultado de uma prática de leitura como exercício de cobrança e de avaliação cognitiva, no qual "a escola transforma a leitura numa atividade maçante, puramente formal para a qual são indiferentes os valores que animam a ler e a discutir os textos lidos" (CHIAPPINI, 2005, p. 177-178). Em muitos casos, o que se observa é uma prática de leitura literária dissociada das experiências de vida e das expectativas dos alunos. Desconsideram-se, nesses casos, as especificidades e as necessidades de alunos para os quais o contato com a literatura poderia contribuir para a sua formação pessoal, escolar e social.

Compreende-se, assim, que é necessário estabelecer uma relação entre o leitor e o texto na qual ambos se complementem: o leitor leva para o texto suas experiências de leitura e seus conhecimentos de mundo; por outro lado, o texto entrega para esse leitor novos conhecimentos a serem aplicados na sua compreensão da realidade cultural na qual ele vive e, também, na realização de outras leituras, visto que o processo de leitura de um texto envolve a exploração do sujeito por ele mesmo. Tal prática não é simples e necessita de tempo e estratégias de leitura capazes de vencer a inércia do sujeito em se envolver com o texto literário e com os sentimentos que ele provoca.

No contexto escolar, a aproximação entre leitor e texto nem sempre ocorre de forma harmônica. Em seus estudos, Annie Rouxel (2013, p. 71) observa que, muitas vezes, os alunos não se interessam pela leitura porque os textos abordados em sala de aula são distantes de sua realidade cultural. Além disso, a leitura escolar ocorre num ritmo que não contribui para que eles estabeleçam uma relação agradável com a obra; a leitura literária passa a ser encarada como uma atividade enfadonha e rejeitada por esses estudantes. Com isso, a leitura de obras literárias que deveria ser uma atividade capaz de proporcionar momentos de fruição estética e aprofundamento da reflexão sobre diversos aspectos da experiência humana, torna-se um momento desinteressante, sem significado para os alunos e prejudicial à própria razão de ser da literatura.

Vale ressaltar que são as primeiras leituras que oferecerão a esses leitores uma gama de conhecimentos e procedimentos que serão por ele 
incorporados e utilizados em situações futuras, na sua relação com outros textos literários. Ressaltando essa perspectiva, Cruz (2012, p. 183) defende que: “é interessante e viável a leitura de clássicos da literatura em ambientes escolares onde reside o mito da dificuldade de compreensão de leitura de qualquer texto que fuja ao padrão de textos curtos e simples". Portanto, a vivência da leitura literária é um desafio para o professor que tem pela frente a formação do leitor crítico, capaz de traduzir e comparar as representações literárias com seu universo social.

\section{Ampliando o horizonte cultural}

Na experiência de leitura aqui apresentada, reconhece-se que a obra literária, com suas múltiplas e surpreendentes formas de representação dos sujeitos que habitam a realidade, pode contribuir para levar o leitor a refletir sobre o fato de que, hoje, as identidades sexuais se apresentam de forma fragmentada, descentrada, fluidas e ambíguas. Assim, ao se permitir acompanhar as ações de determinadas personagens nos seus momentos de intimidade, o leitor também poderá conhecer os sentimentos e os valores que motivam os atos sexuais desses seres. No livro de contos $A$ via crucis do corpo, percebe-se que a autora mantém o tempo todo a consciência de que está fazendo confissões que envolvem a vida sexual de outras pessoas. Com certo constrangimento, ela declara: “Inútil dizer que não aconteceram comigo, com minha família e com meus amigos. Como é que sei? Sabendo. Artistas sabem de coisas" (LISPECTOR, 1998, p. 11).

Nesta incursão pelo universo dos desejos e dos prazeres das personagens do conto "O corpo", oferece-se ao leitor a possibilidade de aprofundar o conhecimento sobre esse importante elemento próprio da condição humana: as diferentes formas de viver a sexualidade. Os relatos íntimos das personagens desse conto serão usados como suporte para o debate acerca da sexualidade. Segundo Foucault, a partir do século XIX, tem se intensificado a confissão voluntária dos prazeres sexuais. E, nesse caso, a confissão não consiste em relatar apenas o ato sexual, mas também, e principalmente, trata-se de "reconstituir nele e a seu redor, os pensamentos e 
as obsessões que o acompanham, as imagens, os desejos, as modulações e a qualidade do prazer que o contém" (1999, p. 63).

Com essa experiência de leitura pretende-se levar o leitor a refletir sobre o fato de que, embora as múltiplas identidades sexuais estejam presentes no mundo atual de forma bastante evidente, há ainda uma noção hierárquica que estabelece uma das variantes como sendo a normal. A partir de sua adequação ou de seu afastamento em relação a esse padrão, a identidade de cada sujeito será submetida a um julgamento pelo grupo social do qual ele faz parte.

Historicamente, o padrão sexual que ainda hoje vigora é construído em torno de uma sexualidade excludente que tem como norma a do "homem branco, heterossexual, de classe média urbana e cristão". Nesse contexto, “serão os 'outros' sujeitos sociais que se tornarão 'marcados', que se definirão e serão denominados a partir dessa referência. Desta forma, a mulher é representada como 'o segundo sexo' e gays e lésbicas são descritos como desviantes da norma heterossexual" (LOURO, 2010, p. 15-16, grifos da autora).

Por esse padrão, as demais formas de viver a sexualidade são consideradas desvios, ou seja, formas indesejáveis de ser. Em contrapartida, a luta pelos direitos humanos é uma constante, quando se defendem as diversas possibilidades de construção das identidades sexuais. A multiplicação dessas identidades corresponde a várias formas de ver e de compreender a sexualidade do outro. Entretanto, de forma cada vez mais declarada, e reivindicando o reconhecimento de sua legitimidade e, portanto, de seus direitos, essas diversas formas de viver a sexualidade ocupam diferentes lugares na sociedade. De acordo com Foucault (1999), muitas sexualidades ocupam espaços interditos, outras são aceitas apenas fora dos espaços familiares. Portanto, a maioria dessas identidades fora do padrão heterossexual é marginalizada pelo senso comum como veremos no debate proposto aos leitores da EJA.

Para Guacira Louro (2010), a sexualidade de cada sujeito apresentase, muitas vezes, de forma ambígua: o indivíduo não se define de forma fechada; sua sexualidade também fica condicionada ao momento vivido e aos outros sujeitos com os quais cada um está em contato. Nesse contexto, o 
leitor pode ampliar sua compreensão sobre as sexualidades híbridas e ambíguas a partir da leitura de obras nas quais a construção de determinadas personagens conteste o padrão socialmente definido.

Tais constatações fortalecem a compreensão de que a leitura literária pode oferecer importantes contribuições para as discussões sobre essa questão identitária e sobre a diversidade de comportamentos sexuais. Nesse sentido, a leitura de determinadas obras, a exemplo do conto $O$ corpo, de Clarice Lispector, além de proporcionar momentos de apreciação estética, também convida o leitor a refletir sobre os conflitos entre as regras estabelecidas pela sociedade e as diversas formas de se viver a sexualidade conforme os interesses particulares de cada sujeito. No processo pedagógico, apresenta-se também a possibilidade de se discutir sobre os preconceitos ligados às diferentes sexualidades, propondo a convivência com a diversidade sexual como parte dos direitos humanos e princípio do respeito mútuo.

\section{Oficinas de leitura}

Na realização das atividades que integram as oficinas de leitura, foi aplicada a prática cultural de leitura (GOMES, 2014), partindo da premissa de que a interpretação do texto literário é guiada pela formação cultural do leitor. Esse método propõe que, levando em conta o horizonte de expectativas dos alunos, determinado por suas vivências anteriores, o professor provoque situações que propiciem o questionamento desse horizonte cultural por meio do debate sobre questões identitárias relativas ao gênero e à sexualidade.

Evidencia-se, desse modo, a importância de fortalecer nos jovens leitores uma postura ativa no processo de construção de significados do texto a partir do horizonte cultural dos leitores que participam da oficina de leitura. Com a aplicação desse método, pretende-se observar como se processou a recepção do texto literário pelos alunos e como essa leitura atuou para alterar o horizonte de expectativas que eles já possuíam sobre as identidades sexuais do texto literário.

Com isso, ao mesmo tempo em que esses leitores emprestam ao texto conhecimentos acumulados em suas experiências culturais, também 
recolhem dele novos conhecimentos sobre as questões culturais representadas no texto literário. A partir dessa troca de conhecimentos, o leitor amplia sua visão sobre a temática cultural abordada e o texto passa por um processo de renovação, uma vez que a ele foram incorporados os conhecimentos oferecidos por mais um leitor, conforme Rouxel (2013).

A primeira etapa da realização do trabalho de leitura atendeu ao objetivo de detectar, através da aplicação de um questionário, os conhecimentos prévios que os alunos já possuíam a respeito das identidades sexuais contemporâneas. Esse questionário compunha-se de cinco proposições frente às quais os alunos deveriam se posicionar sobre temas como a bigamia, a homossexualidade masculina e feminina, o adultério e a traição. As respostas apresentadas pelos alunos ajudariam o professor a identificar os conhecimentos que precisariam ser mais trabalhados para que a interpretação dos textos se processasse de forma mais ampla.

Na segunda etapa, promoveu-se a leitura de textos jornalísticos para atender ao horizonte de expectativas dos leitores detectado na etapa anterior. Os textos lidos nesta etapa compõem a unidade temática Diversidade sexual do livro didático que os alunos já possuíam - Alcance EJA: Língua portuguesa 3 . O primeiro deles, intitulado Preconceito em pauta ${ }^{4}$ propunha algumas discussões sobre diferentes formas de preconceito de que são vítimas os membros da comunidade LGBT e, também, algumas ponderações sobre a implantação de leis que criminalizem atos motivados pela homofobia. $\mathrm{O}$ segundo texto constituía um trecho do artigo Governo lança política de saúde para público LGBT no SUS $^{5}$ e nele se discutiam questões relacionadas à homossexualidade, à transexualidade, à homofobia, e à necessidade de que sejam garantidos os direitos do público LGBT no que se refere ao atendimento na rede pública de saúde.

${ }^{3}$ Obra didática organizada por Laura Volp, publicado em 2013 pela Editora Positivo e destinada aos anos finais do Ensino Fundamental. Constitui um material disponibilizado pelo Programa Nacional do Livro Didático - PNLD - para os alunos das escolas públicas do Brasil.

${ }^{4}$ Preconceito em pauta. Folha de S. Paulo, São Paulo, dez, 2011. Opinião, Caderno 6.

${ }^{5}$ NUBLAT, Johanna. Governo lança política de saúde para público LGBT no SUS. Folha de S. Paulo, 1 dez. 2011. Equilíbrio e saúde. 
Atendido o horizonte de expectativas dos alunos, para promover a ruptura do horizonte de expectativas dos leitores, foi realizada a leitura do conto $O$ corpo. Essa narrativa descreve o cotidiano de uma família fora do padrão composta por um homem, Xavier, e duas mulheres, Beatriz e Carmem. Essa relação passa a ser assombrada pela presença de uma prostituta. Infelizes com a traição do marido, as duas esposas se vingam de forma trágica. Essa etapa de leitura levou em consideração o estranhamento que a obra literária provocou nos alunos, visto que ela se distanciava do horizonte de expectativas tradicional ao descrever um casamento bígamo e cenas homoeróticas entre duas mulheres.

No primeiro momento desta etapa, foi realizada a apresentação do livro $A$ via crucis do corpo. Na sequência, para que os alunos refletissem sobre o ato de ler histórias e sobre o trabalho criativo de Clarice Lispector, o professor expôs alguns trechos do texto Explicação, no qual a autora reflete sobre o fazer literário, a recepção da sua produção por determinados leitores e, também, sobre a temática cultural abordada nos contos que compõem aquela obra - a fragmentação da sexualidade dos sujeitos contemporâneos: "Uma pessoa leu meus contos e disse que aquilo não era literatura, era lixo. Concordo. Mas há hora para tudo. Há também a hora do lixo" (LISPECTOR, 1998, p. 12).

Em seguida, os alunos realizaram uma leitura silenciosa do conto $O$ corpo. Após essa atividade, eles foram incentivados a fazer comentários e expor questionamentos sobre o texto com base em perguntas lançadas pelo professor com o propósito de verificar quais as características que mais lhes chamaram a atenção na construção das personagens, considerando a forma como cada uma delas vivia a própria sexualidade. Nessa etapa, surgiram questões também relacionadas aos ambientes dessas personagens. Destaca-se o incômodo que a inserção da prostituta causou ao desfecho da narrativa. Essa personagem provocou o desequilíbrio na relação entre as personagens que compunham o triângulo amoroso e, consequentemente, o desequilíbrio na própria narrativa. Nessa conversa foram discutidas, então, questões relacionadas à poligamia, à prostituição, ao homossexualismo feminino e ao adultério. 
No segundo momento desta etapa do trabalho, os alunos foram instruídos a produzir um texto no qual registrassem aquilo que mais thes chamou a atenção no texto lido na atividade anterior, considerando a forma como ele foi escrito, a trajetória de cada personagem e as situações vividas por elas na busca pela realização de seus desejos sexuais. Com esse registro feito pelos alunos, o professor atendeu ao objetivo de coletar material para observar como se deu a recepção desse conto e até que ponto tal leitura rompeu o horizonte de expectativas anterior.

Na etapa seguinte, para que os leitores revissem e aprofundassem os conhecimentos adquiridos a partir da leitura do texto de Clarice Lispector, o professor promoveu um debate sobre as impressões apresentadas pelos alunos a respeito do conto. Foram apresentados aos alunos questionamentos sobre alguns conceitos e valores levantados nos textos produzidos por eles mesmos. Houve a necessidade de que o professor esclarecesse algumas dúvidas sobre os aspectos legais de um homem ser casado com duas mulheres.

Para finalizar o trabalho de leitura desse conto, no segundo momento desta etapa, foi realizada a exibição do filme $O$ corpo $o^{6}$. A exibição dessa adaptação cinematográfica atendeu ao propósito de promover uma nova leitura da obra de Clarice Lispector a partir da linguagem audiovisual. Após a exibição dessa obra, os alunos foram estimulados a fazerem associações entre o filme e o texto lido, ressaltando as semelhanças e as diferenças entre as duas linguagens. A opção pela exibição do filme somente após todo o trabalho de leitura e análise da obra escrita atendeu ao interesse de não direcionar a leitura do conto a partir da representação proposta no filme.

No procedimento adotado para a exibição dessa obra audiovisual, considerou-se que, para promover a exibição de um filme que dialoga ou que é uma adaptação de uma obra literária, o professor deve observar se esse livro

${ }^{6}$ Filme de 1991, adaptação da obra de Clarice Lispector realizada pelo diretor José Antônio Garcia, com Antônio Fagundes, Marieta Severo e Cláudia Jimenez nos papéis principais. Disponível no endereço eletrônico https://www.youtube.com. Acesso em 10 de ago. de 2016. 
já foi lido pelos alunos, ainda que apenas alguns de seus fragmentos, para que, dessa forma, possa sugerir uma leitura que se realize através da comparação e do contraste que se estabelecem entre as duas linguagens, de tal modo que sejam observadas as especificidades de cada uma delas (THIEL; THIEL, 2009, p. 48). Evitou-se, assim, que os leitores já realizassem a leitura do texto tendo em mente a materialização de determinados elementos do conto.

Na última etapa desse trabalho, com o propósito de ampliar o horizonte de expectativas do leitor, o professor apresentou slides no Datashow, enfatizando as ambiguidades sexuais representadas no conto de Clarice Lispector. Em seguida, foi promovido um debate no qual, os alunos fizeram comentários sobre as personagens ficcionais a partir de algumas provocações lançadas pelo professor. Assim, foram discutidas questões sobre as características sociais das personagens, considerando aspectos físicos e psicológicos de cada uma delas. Para complementar essa atividade, foi solicitada aos alunos a produção de um texto, expondo a compreensão que eles tiveram sobre a obra lida.

A partir desses textos foram coletadas informações sobre a recepção do conto e, na aula seguinte, foi promovida uma última conversa com os alunos a respeito da temática abordada ao longo dessa oficina de leitura. Durante tal conversa, foram levantados diversos termos referentes à diversidade sexual presente nos textos lidos, como homossexualidade, LGBT, transexualidade, gays e homofobia. Para esclarecer as dúvidas sobre esses termos, o professor estimulou a discussão e a pesquisa em dicionários, publicações e páginas da internet.

Ao fim da realização das atividades descritas anteriormente, a partir do material coletado ao longo de todo o processo de leitura, o professor procedeu ao trabalho de levantamento de dados que expressassem como se deu a recepção dos textos pelos alunos. Destaque-se que, já durante a execução de cada uma das etapas, foi necessário refletir sobre a forma como os alunos reagiram a cada atividade proposta pelo professor e sobre os resultados alcançados a cada passo do trabalho. 


\section{Análise dos dados da recepção}

A realização das atividades de leitura atendeu ao objetivo de observar como os alunos receberam os textos selecionados para a pesquisa e que conhecimentos eles aplicaram para produzir significados para essas obras literárias. Os dados obtidos serviram de referência para a sistematização de uma proposta de leitura literária direcionada, em princípio, aos alunos da EJA, podendo ser aplicada também em turmas do Ensino Fundamental regular. Na primeira parte desse trabalho de análise de dados, o pesquisador deteve-se sobre as respostas apresentadas pelos alunos no questionário de sondagem aplicado na primeira etapa do método de leitura. Abaixo, apresentam-se alguns pontos das análises realizadas a partir do material coletado.

Para a maioria dos alunos já há o conhecimento de que a bigamia pressupõe a identificação de um sujeito como sendo, de uma só vez, o cônjuge de duas mulheres. Chamou a atenção o fato de que, para um número considerável de alunos, mesmo quando o homem mantém relacionamentos esporádicos fora do casamento, ele já é identificado como sendo um homem bígamo. Por outro lado, um número mínimo de alunos associou a bigamia com a prostituição. Com relação às ideias de infidelidade e de adultério, observouse que para a maioria dos alunos deve prevalecer o princípio de que o homem adúltero deve ser castigado de alguma forma. Atente-se para o fato que um número considerável de alunos prevê que para um adúltero, o melhor castigo é passar a ser também vítima do adultério, o que implica dizer que, para esse grupo de alunos, uma mulher vítima de traição por parte de seu marido estaria autorizada a traí-lo.

Chamou a atenção o fato de que há entre os alunos uma visível confusão em relação ao conceito de homossexual. Já com relação ao conceito de bissexualidade, constatou-se que os alunos consideram que um sujeito que satisfaz seus desejos sexuais tanto com homens quanto com mulheres está agindo em desacordo com os comportamentos que a sociedade determina para seus membros na esfera da sexualidade. Para eles, a identidade sexual de cada sujeito deve estar inserida num contexto cultural no qual as regras são estabelecidas pelo grupo e aqueles que não as respeitam acabam por se tornarem mal vistos na sociedade. Evidenciou-se, assim, a necessidade de 
promover estudos sobre os termos homossexual, bissexual e heterossexual dando aos três um tratamento que não os hierarquizasse, isto é, sem estabelecer que nenhum deles fosse considerado desviante em relação ao outro.

Uma vez analisados os dados estatísticos apresentados acima, o professor procedeu à análise dos resultados obtidos ao longo da realização da experiência de leitura. Nesse momento, com base nos textos produzidos pelos alunos sobre o conto $O$ corpo, de Clarice Lispector, foram coletadas importantes informações sobre como esses leitores compreendem duas importantes questões: as relações que se estabelecem entre a literatura e a realidade e a complexidade da temática das identidades sexuais contemporâneas. A seguir, são apresentados alguns dados destacados no material produzido pelos alunos e uma possível análise sobre os pontos destacados nos textos desses leitores.

Observe-se, inicialmente, como alguns alunos se expressaram a respeito da relação entre pessoas e personagens, entre a literatura e a realidade: “É uma história que o marido vive com as duas e o nome é Xavier, Beatriz e Carmem e é normal viver tudo junto. Se fosse na verdade elas ia se matar de brigar. Só porque é história de livro é tudo diferente"” (Aluno 01). Sobre essa relação entre o mundo real e o mundo das personagens, Antonio Candido (2004, p. 55) observa que, "há afinidades e diferenças essenciais entre o ser vivo e os entes de ficção, e que as diferenças são tão importantes quanto as afinidades para criar o sentimento de verdade, que é a verossimilhança". Na compreensão dos alunos, não é necessário haver uma correspondência absoluta entre a literatura e a realidade: a ficção representa para eles o universo em que tudo é possível, diferente da vida real em que existem limitações e condicionamentos.

Alguns alunos, na tentativa de produzirem significados para o texto lido, associaram as experiências vividas pelas personagens a situações que eles já presenciaram ou tomaram conhecimento: “Meu avô tinha duas mulher

\footnotetext{
${ }^{7}$ Nos trechos apresentados como exemplos, foram mantidas a grafia das palavras e a construção das frases conforme o registro feito pelos alunos.
} 
e quando morreu as duas receberam dinheiro e minha avó ficou com raiva e meu tio disse que esse país só tem direito quem não presta porque minha avó era casada de papel e a outra não e ficou tudo a mesma" (Aluno 05). Esses leitores demonstram possuir conhecimentos culturais (inclusive legais) que, sem uma precisão rigorosa, já contribuem para que eles desempenhem a tarefa de fazer comparações entre as identidades ficcionais e aquelas historicamente produzidas em diferentes situações para, dessa forma, produzirem um conjunto de referências que são aplicadas no trabalho de interpretação do texto literário (GOMES, 2014, p. 33).

Alguns alunos se manifestaram sobre a importância que o olhar dos outros deve (ou não) ter sobre a sexualidade de um sujeito. Observe-se como um aluno se manifestou a esse respeito: "A historia que li tem coisas boas e ruins. Bom porque ninguém liga pru modo de vida dos outros e os três faz o que quer da vida ninguém tem a ver. Eles vão pra igreja, pra outro país e pru restaurante" (Aluno 07). Importa lembrar que, conforme Louro, cada sujeito reconhece os outros a partir do lugar social que ele mesmo ocupa (LOURO, 2010, p. 12). Compreende-se, assim, que cada aluno desenvolveu sua análise sobre as personagens do conto tendo como parâmetro, em princípio, sua própria forma de viver, seus conceitos e seus preconceitos sobre diferentes aspectos da sexualidade.

Convém destacar ainda que alguns desses leitores já expressaram um juízo de valor sobre a obra lida. No título de seu texto, um aluno assim se expressou: "li essa historinha ruim". Outro aluno assim se manifestou: "Que história mais feia e sem graça. Não gostei”. E outro fez ainda um interessante questionamento ao fim de seu texto: "Não gosto de ler história de gente que mata uns os outros pois o mundo já tem muito disso e até nos livros tem essas histórias?" Em todos esses comentários, observamos o quanto o texto literário produziu o incômodo e provocou uma reação nesses leitores.

Na prática de leitura, enfatizou-se a plurissignificação dos sentidos das palavras e o quanto Clarice Lispector explorava recursos que produziu a ambiguidade sexual de suas personagens. A maioria dos leitores se concentrou nos aspectos temáticos, mas o riso e o choque também foram identificados como parte do processo prazeroso de leitura. 
Quanto à ampliação do horizonte de expectativas, as aulas foram muito importantes para a inclusão do debate acerca dos direitos individuais e do respeito à diferença do outro. Em muitos casos, os alunos conseguiram produzir textos em que manifestaram a defesa da escolha e da vivência da liberdade sexual. Porém, a maioria ressaltou a punição como uma forma de castigo para aqueles que traem em seus relacionamentos.

\section{Considerações finais}

No desenvolvimento desta pesquisa evidenciou-se a importância de valorização dos conhecimentos culturais que os alunos da EJA empregam no trabalho de interpretação de uma obra literária. A partir desta constatação, ressalta-se que esses estudantes sejam estimulados a colaborarem no processo de interpretação do texto literário empregando seu próprio repertório cultural no trabalho de preencher os espaços vazios deixados no texto e, assim, produzirem o significado para a obra como nos sugere os estudos de Humberto Eco (2004, p. 37). Importa observar que essa leitura baseada na atuação do sujeito leitor - que emprega seus conhecimentos e suas experiências pessoais para atualizar os significados da obra - não constitui, de acordo com Langlade (2013, p. 37), uma abordagem ingênua e limitadora da obra literária; pelo contrário, ao fazer essa associação entre seus próprios conhecimentos e os conhecimentos que o texto oferece, o leitor contribui para ampliar o universo de significados possíveis para uma produção literária.

Durante a realização dessa proposta de leitura na qual se discutiu sobre as identidades sexuais das personagens de ficção em relação às identidades sexuais de sujeitos da realidade contemporânea, dois questionamentos logo se apresentaram para o professor: quais as identidades sexuais que os alunos identificam em seu meio cultural? E quais os conceitos (e preconceitos) que esses leitores possuem sobre essas identidades com as quais eles convivem na sociedade? Com a realização das atividades de leitura pôde-se observar que os alunos já reconhecem diversas identidades sexuais que circulam pela sociedade, embora nem sempre reconheçam a legitimidade de algumas delas. 
Nesta prática, os alunos reconheceram o caráter múltiplo das identidades contemporâneas, uma vez que eles compreenderam que cada personagem, embora tivesse a identidade sexual como um elemento marcante em sua composição, também possui outras identidades que atuam em determinadas circunstâncias e em determinadas situações de interação social. Motivados pelo contato com as personagens dos contos e pelas situações vividas por elas, os alunos refletiram sobre temas como bissexualidade, poligamia, homossexualidade masculina e homossexualidade feminina, adultério e prostituição.

Com essa experiência, as identidades sexuais do contexto do leitor são aproximadas das identidades representadas na ficção. Esse processo é fundamental para a ampliação cultural do horizonte do leitor, que desenvolve o gosto pela leitura "como uma prática de reflexão social" (GOMES, 2014, p. 25). Assim, é fundamental que o trabalho de leitura literária seja realizado a partir de procedimentos que valorizem tanto os aspectos estéticos quanto os culturais representados no texto. No caso estudado, os leitores foram estimulados a refletir tanto sobre a forma como Clarice Lispector aborda o tema da sexualidade em seu conto, como também sobre as normas e regras que controlam essas identidades no contexto social. Com isso, os significados do texto são atualizados através do trabalho colaborativo do leitor.

\section{Referências}

CHIAPPINI, Lígia. Leitura e Interdisciplinaridade. In: Reinvenção da catedral: língua, literatura, comunicação: novas tecnologias e políticas de ensino. São Paulo: Cortez, 2005. p. 169-181.

CRUZ, Maria de Fátima Berenice. Leitura literária na escola: desafios e perspectivas de um leitor. Salvador: Eduneb, 2012.

ECO, Umberto. Lector in fabula. São Paulo: Perspectiva, 2004.

FOUCAULT, Michel. História da Sexualidade I: A Vontade de Saber. Trad. Maria Thereza da Costa Albuquerque e J. A. Guilhon Albuquerque. 13. ed. Rio de Janeiro: Edições Graal, 1999. 
GOMES, Carlos Magno. Ensino de Literatura e Cultura: do resgate à violência doméstica. Jundiaí: Paco Editorial, 2014.

LANGLADE, Gerard. O sujeito leitor, autor da singularidade da obra. Trad. Rita Jover-Faleiros. In: ROUXEL, Annie, et al. (Org.). Leitura subjetiva e ensino de Literatura. São Paulo: Alameda, 2013. p. 25-38.

LISPECTOR, Clarice. A via crucis do corpo. Rio de Janeiro: Rocco, 1998.

LOURO, Guacira Lopes. Pedagogias da sexualidade. In: $O$ corpo educado: pedagogias da sexualidade. Guacira Lopes Louro (Org.). Trad. Thomaz Tadeu da Silva. 2. ed. Belo Horizonte: Autêntica, 2010. p. 9-34.

ROUXEL, Annie. Autobiografia de leitor e identidade literária. Trad. Neide Luzia de Rezende. In: Leitura subjetiva e ensino de Literatura. São Paulo: Alameda, 2013. p. 67-83.

THIEL, Grace Cristiane; THIEL, Janice Cristine. Movie takes: a magia do cinema na sala de aula. Curitiba: Aymará, 2009.

XAVIER, Elódia. Prefácio de Leituras Literárias: mito, gênero e ancestralidade. In: GOMES, Carlos Magno; RAMALHO, Christina e CARDOSO, Ana Maria Leal. (Org.). Leituras Literárias: mito, gênero e ancestralidade. São Cristóvão: EDUFS, 2014.

Recebido em 15 de novembro de 2016.

Aceito em 4 de dezembro de 2016. 